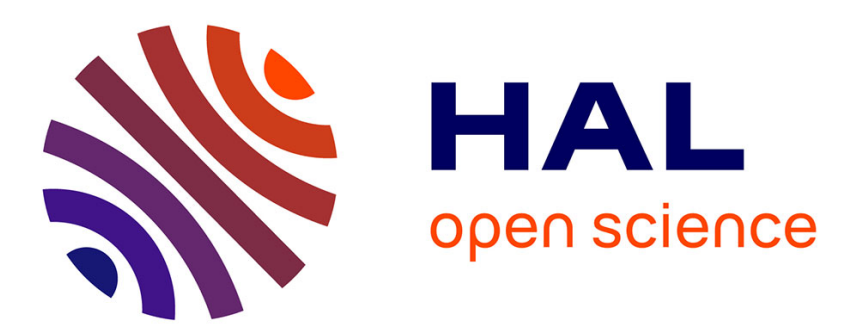

\title{
Conceptual Design of a Software Tool for Management of Biological Invasion
}

Peter A. Khaiter, Marina G. Erechtchoukova

\section{To cite this version:}

Peter A. Khaiter, Marina G. Erechtchoukova. Conceptual Design of a Software Tool for Management of Biological Invasion. 12th International Symposium on Environmental Software Systems (ISESS), May 2017, Zadar, Croatia. pp.209-220, 10.1007/978-3-319-89935-0_18 . hal-01852646

\section{HAL Id: hal-01852646 \\ https://hal.inria.fr/hal-01852646}

Submitted on 2 Aug 2018

HAL is a multi-disciplinary open access archive for the deposit and dissemination of scientific research documents, whether they are published or not. The documents may come from teaching and research institutions in France or abroad, or from public or private research centers.
L'archive ouverte pluridisciplinaire HAL, est destinée au dépôt et à la diffusion de documents scientifiques de niveau recherche, publiés ou non, émanant des établissements d'enseignement et de recherche français ou étrangers, des laboratoires publics ou privés. 


\title{
Conceptual design of a software tool for management of biological invasion
}

\author{
Peter A. Khaiter ${ }^{1}$, and Marina G. Erechtchoukova ${ }^{1}$ \\ ${ }^{1}$ School of Information Technology, Faculty of Liberal Arts and Professional Studies, York \\ University, 4700 Keele Street, Toronto, Ontario M3J 1P3 Canada \\ pkhaiter@yorku.ca, marina@yorku.ca
}

\begin{abstract}
Invasion of alien species is recognized as one of the most pressing global challenges altering the composition, structure and functioning of invaded ecosystems as well as the services they generated before the invasion. We consider the case of Norway maple (Acer platanoides) which was intentionally introduced to North America as an ornamental street shade tree, but now has been viewed as a serious threat to native forest ecosystems in the United States and Canada. Decisions about the management of invasive cases are inherently difficult because of the multifactorial and multiattribute scope of the problem. To facilitate management efforts, decision-makers and environmental practitioners require a software tool integrating relevant knowledge and acting as a supporting expert. The underlying methodology, conceptual design of the tool and its main modules are discussed in the paper. In particular, we argue for an approach taking into account the entire ecosystem purview of the problem, phases of invasion process, tree development stages and driving mechanisms underlying the cases of biological invasion. Functional architecture of a software tool for environmental modelling and decision making in managing of invasive cases (EMDMIC) is presented. Largely, the EMDMIC consists of the three main modules: "Factors", "Ecosystem Modelling” and "Management". Functionality of each module is articulated in the paper. At the current stage of architectural design, the principles of multi-layered designs and platform independence have been applied. The latter enable to keep the options for future implementations of the tool open and also makes it potentially suitable for various targeting environments.
\end{abstract}

Keywords: Invasive species · Ecosystem · Norway maple · Software tool · Functional architecture · Decision-making.

\section{Introduction}

Biological invasion of nonnative species is considered as one of the major threats to sustainable development and as a major danger to marine and terrestrial biodiversity (Molnar et al. [24]; Hughes and Worland [12]). Alien species are seen as one of the primary means for human-accelerated global change: they pose a threat to biodiversity, re-work ecosystem arrangements, tasks and services, and induce huge economic costs and serious health complications to humans (Mazza et al. [23]). The effects of having

adfa, p. 1, 2011.

(C) Springer-Verlag Berlin Heidelberg 2011 
no control in place for invasion species could be costly in terms of both direct monetary values and the negative consequences for human life (Andersen et al. [1]).

In the present study, we focus on the case of Norway maple (Acer platanoides). This plant species was introduced intentionally from continental Europe during the mid1700 s to eastern North America (initially to Philadelphia around 1760) as an ornamental shade tree and then widely planted during the latter half of 20th century (Webb et al. [39]; Wangen and Webster [38]). Nowadays, it has invaded northeastern forests of the United States and the riparian and mesic montane forests of the northern Rocky Mountains (Reinhart et al. [31]). A. platanoides has been recognized as a serious threat to native forest ecosystems in the United States and Canada.

The scales of invasive spread call for managerial actions aimed at the protection and restoration of native ecosystems (e.g., removal of A. platanoides from invaded areas, Webb et al. [39]) which are associated with considerable difficulty and expense and whose effect is not easily foreseeable due to the complexity and substantial non-linearity of the contributing factors and processes. To facilitate the management efforts, decision-makers and environmental practitioners should be equipped with a software tool integrating relevant knowledge and acting as a supporting expert.

\section{Methodology}

Biological invasion is a complex phenomenon making decisions about management of invasive cases inherently difficult because of the multifactorial and multiattribute scope of the problem, a great level of uncertainty regarding the outcomes of possible management actions, multiple, sometimes conflicting, objectives and numerous parties involved in the process (Maguire, 2004). In the sub-sections below, we discuss some important aspects of the problem.

\subsection{Phases of invasion process}

The process of plant invasion comprises certain stages (Fig. 1). Thus, Radosevich et al. [30] defined three phases: introduction, colonization and naturalization. Wangen and Webster [38] paralleled them with the phases of stratified diffusion by Shigesada et al. [34]. Andersen et al. [1] argued for four phases of entry, establishment, spread and impact. In the latter classification, the entry phase marks the arrival of a non-indigenous species into a new environment; the establishment phase occurs where this arriving population begins to reproduce in situ and escapes immediate danger of local extinction; in the spread phase, the species disperses from its initial site of establishment and occupies available habitat within its new environment; and in the impact phase, an established species persists and competes in its new geographical range (Andersen et al. [1]). 


\begin{tabular}{|c|c|c|}
\hline Introduction & Colonization & Naturalization \\
\hline Entry & Establishment & Spread \\
\hline
\end{tabular}

Fig. 1. Phases of invasion process (after Radosevich et al. [30]; Andersen et al.[1])

\subsection{Tree development stages}

The starting point in the tree life history is seed planting (Fig. 2). Surviving seeds will germinate and establish the seedlings. Seedlings are defined as trees whose height does not exceed the maximum seedling height for a given species (e.g., $1.00 \mathrm{~m}$, Wyckoff \& Webb [41]; 1.35 m, Murphy [26]). Accordingly, seedlings have no diameter at breast height $(\mathrm{DBH})$; their primary size measurement is the diameter at a height of $10 \mathrm{~cm}$ (diam10). When a seedling reaches the maximum seedling height, it becomes a sapling, for which a DBH is greater than 0 and less than the minimum adult DBH (Murphy [26]). The sampling phase continues until the tree reaches a specific threshold height (e.g., $3 \mathrm{~m}$; Senbeta and Teketay [33]) or the minimum adult DBH (e.g., $2.5 \mathrm{~cm}$, Wyckoff \& Webb [41]), after which it becomes adult. Snags are standing dead trees which are produced when either saplings or adults die due to normal tree mortality or a disturbance event, such as disease. Fallen snags form woody debris.

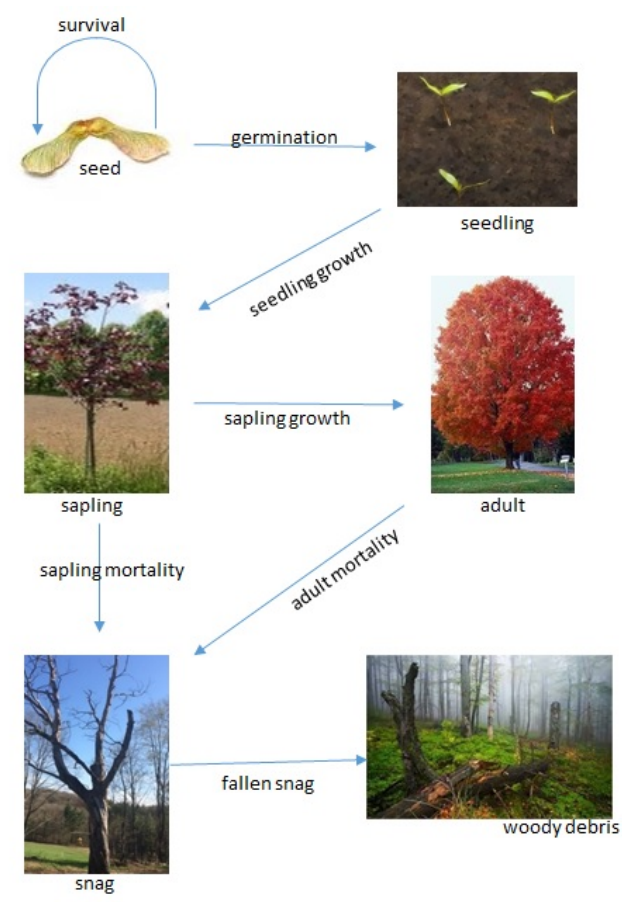

Fig. 2. Tree development stages 


\subsection{Ecosystem scope}

It is commonly accepted that alien species produce substantial negative effects on the composition, structure and functioning of the invaded ecosystems (e.g., Higgins et al. [10]; Wangen and Webster [38]). Therefore, the ecosystem scope needs to be taken into consideration in the analysis for decision-making associated with invasive cases. The introduction of nonnative species is a stress onto invaded ecosystems, and this stress, in most of the cases, will be compounded with, and possibly amplified by, other natural and anthropogenic influences. The impacted ecosystem, its components and functions will react to stress in different ways. A typology of ecosystem stresses (sensu Khaiter and Erechtchoukova [15]; Gutiérrez et al. [8]) enables differentiation between specific categories of stress, on the one hand, and the distinct functions and ecosystem components (biotic and abiotic) being influenced, on the other.

Furthermore, it is important for practical environmental management to predict the persistence capacity and probable transformations in invaded ecosystems. It has been demonstrated (Khaiter and Erechtchoukova [14]) that there are common patterns in the behaviour of ecosystems as they respond to exogenous disturbances, and the following five scenarios in ecosystem stress dynamics have been determined: (1) resistance; (2) deformation; (3) resilience; (4) degradation; and (5) shift. To predict a particular scenario, a good understanding of the impact mechanisms driving the changes is necessary, but by far, it remains rather limited (Reinhart et al. [31]).

\subsection{Driving mechanisms}

From the ecosystem perspectives, persistence to invasion occurs in the form of competition from the native communities (Martin and Marks [22]), and a dominating concept since seminal paper by Elton [6] has been that resistance to invasion is greater in intact or undisturbed communities. However, recent studies are not so definitely supportive of this paradigm (e.g., Webb et al. [39]) and rather unveil a more complicated interplay of biotic and environmental drivers in the resulting ecosystem resistance to biological invasion.

In addition, competition with resident species can take on multiple forms - e.g., in the cases of woody invasion in forest ecosystems, for light, soil nutrient resources, as allelopathic interference and disruption of mycorrhizal associations (Urgenson et al. [35]). However, invasive plant species may bring novel symbiotic mutualisms into the ecosystem (Vitousek et al. [36]). The resistance to invasion in forest ecosystems can be modified by environmental factors, such as soil moisture and nutrient levels (e.g., nitrogen, Walters and Reich [37]) or soil pH. Strongly acidic soils offer the highest resistance to invasion, while base-rich soils can significantly reduce invasion resistance (Martin and Marks [22]). The outcome of this competition can affect critical functional roles in both terrestrial and adjacent aquatic habitats: regulating microclimate, stabilizing stream banks and water flow and providing energy and nutrients to soil and aquatic food webs (Urgenson et al. [35]), i.e., ecosystem services. 


\section{EMDMIC design}

In this section, the development of a software tool for environmental modelling and decision making in managing of invasive cases (EMDMIC) is presented. Following its introduction (Khaiter et al. [16]), architectural design and detailed aspects are considered in the paper. Though the motivation for the study has been the case of Acer platanoides, there are good reasons to believe that the suggested software tool is suitable for a broader range of biological invasions in forest ecosystems. The tool consists of the three main modules (Fig. 3): "Factors", "Ecosystem Modelling" and "Management" which are discussed in the corresponding sub-sections below.

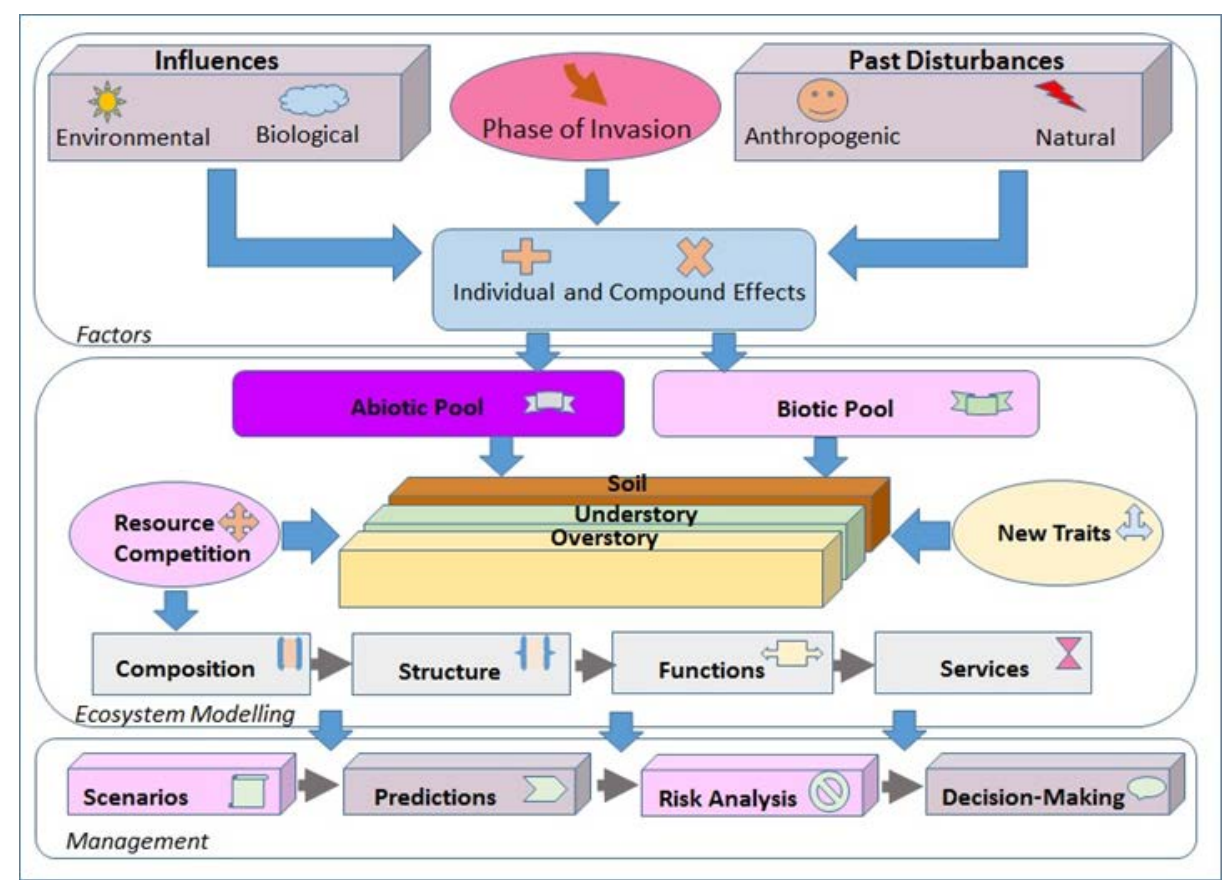

Fig. 3. The EMDMIC functional architecture

\subsection{Module "Factors"}

The "Factors" module specifies a particular stage of the invasion process (see sub-section 2.1) as well as environmental factors (e.g., topology, geology, soil composition, hydrology and meteorology, including the annual insolation above the forest canopy, Botkin et al. [3]) and biological factors (e.g., shade tolerance, soil nutrient cycling, phenotypical plasticity, animal and plant parasites and pollinating insects, etc.) creating 
traits for invasion. In particular, studies on A. platanoides unveiled such invasive advantages of this tree species as:

- high shade tolerance and adaptation;

- light interception that reduces light availability (both quantitatively and qualitatively) for native communities (e.g., Reinhart et al. [31]);

- physiological mechanisms including early leaf expansion and late leaf drop for a longer growth season compared to native species (Webb et al. [39]);

- allocation plasticity (Urgenson et al. [35]) changing patterns of dominance due to higher inherent growth rate, by increasing nutrient availability (i.e., Ca, Mg, K, N) and their recycling rates (Gómez-Aparicio et al. [7]).

Ultimately, these specific properties of A. platanoides form important drivers of native suppression, leading to decreased survival and growth of native species (e.g., Reinhart et al. [31]). The module "Factors" will take into account the history of past disturbances experienced by the ecosystem under consideration, both natural (e.g., fire, flooding, extreme weather events, diseases, herbivory, etc.) and anthropogenic (e.g., pollution, habitat destruction, introduced pets and pathogens, logging, climate change, dam and road construction, etc.). As the outcome, the module implements an assessment of individual and compound effects of the contributing factors from the perspective of potential drivers creating favourable conditions for successful invasion of nonnative species (e.g., Reinhart et al. [31]).

The entry phase of invasion is characterized by the native tree canopies and exotic invaders attempting to establish themselves in the understory. The dynamics of the process may vary with a particular tree development stage. For example, the establishment of seedlings is viewed as a key phase in forest succession (Martin and Canham [20]; Morrison and Mauck [25]) during which closely related species are more likely to compete against each other on the basis of their shared characteristics (Lapointe and Brisson [17]). Comparing very similar native and exotic congeners (e.g., A. sacharum and $A$. platanoides) in situ, it is recommended to identify which traits promote invasiveness (Mack [18]). In particular, while observing that Norway maple is highly shade-tolerant, it was reported that this species is more shade-tolerant as a seedling than as a maturing tree (Nowak and Rowntree [27]; Wyckoff \& Webb [41]), thus, conferring it invasive advantages by enabling to dominate in the understory and displace or diminish the native $A$. sacharum during the seedling stage.

\subsection{Module "Ecosystem Modelling”}

The "Ecosystem Modelling" module provides a formalized description of the invaded ecosystem. The abiotic (or non-living) pool includes physical factors (e.g., temperature, light, pressure, energy, acidity measure, soil depth, soil moisture-retention capacity, etc.) and chemical factors (e.g., oxygen, carbon, phosphorus, nitrogen, sulphur, calcium, etc. levels and availability). The biotic (or living) pool is organized in hierarchical 
structures of organisms depending on their roles in the energetic and metabolic processes at the overstory, understory and soil levels. Invaders will compete with native species for resources (e.g., light, space, mineral nutrients, etc.), and new traits in the ecosystem can be formed as a result (e.g., novel symbiotic mutualisms, means of acquiring resources, adaptation plasticity, allelopathic compounds, amplifying of native traits, etc.).

The invasion of alien species will alter the composition, structure and functioning of the invaded ecosystem as well as the services it generated before the invasion occurred. The ultimate task of this module is to predict any such transformations. Some of the computational formulae are shown in (1)-(6). Seed germination is estimated as:

$N S G=\% G * N S P$,

where NSP, NSG are number of seeds planted and germinated, respectively; \%G is germination rate, as defined by Ologundudu et al. [28]. The cumulative growth of biological organisms at the juvenile phase occurs with the accelerating rate, at the mature phase - with the constant rate and at the senescent phase - with the decelerating rate. The lifespan cumulative growth curve (CGC) is, thus, sigmoidal, and a growth variable (e.g., DBH, height, volume, etc.) can be found from the following formula (Brack and Wood [4]):

$D B H=\exp \left(a+\frac{b}{T A}\right)$,

where TA is the tree age; $a$ and $b$ are species-specific regression parameters. Non-linear (sigmoidal) growth functions are widely used in developing tree height-diameter relationships (Huang et al. [11]). Zhang[43] investigated the performance of six functions and concluded that each growth function was equally well-fitted to data of ten species collected in the inland Northwest of the United States with a minor superiority of three functions, one of which is the Weibull-type formula (Yang et al. [42]):

$T H=1.37+c *\left[1-\exp \left(-d * D B H^{f}\right)\right]$,

where $T H$ is the total tree height; $c, d$ and $f$ are species-specific parameters. Crown width $(C W)$ can also be estimated as a function of $D B H$ (Peper et al. [29]):

$C W=\exp \left\{\frac{M S E}{2} *[g+h * \log (\log (D B H+1))]\right\}$, 
where MSE is the mean standard error; $g$ and $h$ are species-specific parameters. Light regime in forest is largely determined by the overstory canopy gaps $(C G)$, which can be predicted from:

$C G=D_{i, j}-\left(C W_{i}+C W_{j}\right) / 2$

where $D_{i, j}$ is the distance between two neighbouring trees; $C W_{i}$ and $C W_{j}$ are their respective crown widths. Then, the light level $(\% L)$ will be found as:

$\% L=\frac{C G}{D_{i, j}} * 100 \%$.

In the open, $\% L=100 \%$ (i.e., full sun regime) while for the closed canopies, $\% L=0 \%$. Formulas (5) and (6) are a simplified version of the gap light index by Canham [5].

Table 1. Characteristics of the variables and parameters in (1)-(6).

\begin{tabular}{l|l|l}
\hline Variable symbol & Description & Unit \\
\hline$N S P, N S G$ & Number of seeds planted and germinated & \\
\hline$\% \mathrm{G}$ & Germination rate & $\%$ \\
\hline$T A$ & Tree age & years \\
\hline$D B H$ & Diameter at breast height & $\mathrm{m}$ \\
\hline$T H$ & Total tree height & $\mathrm{m}$ \\
\hline$C W$ & Crown width & $\mathrm{m}$ \\
\hline$D$ & Distance between two neighbouring trees & $\mathrm{m}$ \\
\hline$C G$ & Canopy gap & $\mathrm{m}$ \\
\hline$\% L$ & Light level & $\%$ \\
\hline$a, b, c, d, f, g, h$ & Species-specific parameters & \\
\hline
\end{tabular}

Dependant variables (Table 1) in formulas (1)-(6) are computed under the assumption of optimal (i.e., most favourable) conditions for the dynamics of contributing processes. In reality, they will be affected by environmental, biological and anthropogenic influences which can be factored through the corresponding transformation functions for each affected state variable and for each type of the influence (Khaiter [13]), i.e.:

$x_{i}^{A}=T F_{i, k} * x_{i}^{U}, \quad 0 \leq T F_{i, k} \leq 1, \forall i=1, \ldots, n, \forall k=1, . . K$,

where $x_{i}^{U}$ and $x_{i}^{A}$ are the $i$ th state variable before and after the influence of the $k$ th type 
factor, respectively; $T F_{i, k}$ is the transformation function of the $k$ th type factor on $i$ th state variable. A compound effect of multiple factors can be expressed through the resulting transformation function (TFR) built either from the ecological Liebig's law of the minimum of limiting factors (8) or in the multiplicative form (9):

$$
\begin{aligned}
& T F R=\min _{k=1, . ., r}\left\{T F_{k}\right\}, \\
& T F R=\prod_{k=1}^{r}\left\{T F_{k}\right\} .
\end{aligned}
$$

\subsection{Module "Management"}

The "Management" module generates possible scenarios of management interventions to cope with the invasiveness. It should be noted that measures can be taken at different decision-making levels, which can be divided into three categories: (1) decisions about preventing the entry of potentially invasive species (through existing laws, agreements on ballast water and shipping, etc.); (2) decisions about targeted control of invasive species after they have been introduced, whether purposely or accidentally; and (3) restoration of invaded habitats and ecosystems. For example, to restore an old-growth oak forest at the Washington Grove in Rochester, NY to its original and native state, Rogers [32] recommended a two-step approach. The first step foresees the removal of mature A. platanoides trees from the forest area, along with other invasive species, which would also create open canopy conditions. By also removing A. platanoides trees from the streets near the Grove and replacing them with stress-resistant native trees, the propagule pressure of invaders will be reduced. The second step of the management plan would encourage native species diversity and oak recruitment by installing physical barriers inhibiting disruption of the leaf layer.

Once the set of scenarios is formed, the module executes predictions of ecosystem components, their short- and long-term dynamics, ecosystem persistence capacity and restoration capabilities in response to each potential managerial effort. It takes into account the mechanisms of invasion, typology of stresses and the common patterns in the ecosystem stress behaviour. As it was mentioned above, a high level of uncertainty concerns each phase of the invasion and also when controls are being applied (Maguire [19]). Thus, woody plant invasion of shade-tolerant species can endure periods of suppressed growth before reaching the canopy layer, which, in combination with the long generation time of trees, makes it difficult to perceive as it unfolds, and, hence, difficult to manage in its early stages (Herron et al. [9]; Lapointe and Brisson [17]; Martin et al [21]; Wangen and Webster [38]; Webster et al. [40]).

The resilience limits of invaded ecosystems also remain unclear. Theoretical ecologists question the ability of a forest ecosystem to fully recover to the original, preinvaded state in the face of complex interactions among anthropogenic impacts: forest fragmentation, climate change and the introduction of invasive species (Webb et al. [39]). 
Given various sources of uncertainty and likely significant cost associated with the implementation of controls in view of scarce budgeting resources, a risk analysis becomes a necessary step of the decision-making process. Specific features of risk analysis in application to the cases of biological invasion have been examined by Andersen et al. [1] and Bartell and Nair [2]. The outcome of this module and the entire tool will be a set of recommended measures aimed at addressing the intervention of alien species in the most efficient way and suggesting resilient solutions for the impacted ecosystems.

\section{$4 \quad$ Discussion and conclusions}

In this paper, we presented functional architecture of the software tool and its internal structural logic, focusing on the modelling module as a backbone of the framework. The principles of multi-layered designs and platform independence have been applied at this stage. The latter enable future implementations of the framework suitable for various targeting environments. At the same time, the transition from the current stage of architectural design to detailed design and further to implementation phase of the software tool described above will require the following groups of models:

- models of pre-invaded dynamics of native species and the ecosystem as a whole;

- models of invasive dynamics of the alien species, including mechanisms underlying their invasive success;

- models of invasive-resident species interactions (e.g., competition for light, space, nutrient resources; possible symbiotic mutualisms, etc.) and their modification by biotic and environmental drivers;

- models of persistence capabilities to sustain the invasion and probable transformations in invaded ecosystems;

- models of effect of invasion on critical functions of the ecosystem; that is ecosystem services;

- models predicting ecosystem components, their short- and long-term dynamics, ecosystem persistence capacity and restoration capabilities in response to each potential managerial effort or scenario;

- models aimed at selection of the best possible scenario for managing the invasion

Prior to the realization of the tool, a number of non-trivial issues should also be addressed. This includes, e.g., predictions of the invasive stress dynamics of the ecosystems. It appears that prediction of the invasive potential of a certain alien species to invade a given environment can be viewed as a problem of machine learning and solved by classification algorithms, provided that sufficient volumes of relevant empirical data are accumulated and available. Prediction of endogenous ecosystem dynamics caused by biological invasion and resulting in compositional, structural and functional transformations most likely calls for process-based models. 
There is a view that an integrated ecosystem perspective of invasive species is amenable to mathematical formalization and system dynamic modelling (Gutiérrez et al. [8]), and it is shared by the authors. It also is a subject of our ongoing endeavours on the topic of decision-making and management of biological invasion.

Acknowledgements. The authors would like to express appreciation to all researchers whose publications are referred to in this paper for their field studies and theoretical generalizations on invasive species which inspired our interest towards the topic. The authors are thankful to the editor and anonymous reviewers for their helpful suggestions and comments on the early versions of the manuscript which helped to improve the quality.

\section{References}

1. Andersen MC, Adams H, Hope B, Powell M (2004) Risk analysis for invasive species: general framework and research needs. Risk Analysis 24(4): 893-900

2. Bartell SM, Nair SK (2004) Establishment risk for invasive species. Risk Analysis 24(4): 833-845

3. Botkin DB, Janak JF, Walls JR (1972) Some ecological consequences of a computer model of forest growth. Journal of Ecology 60(3): 849-872

4. Brack CL, Wood GB (1998) Forest mensuration - measuring trees, stands and forests for effective forest management. http://fennerschool-associated.anu.edu.au/mensuration/BrackandWood1998/T_GROWTH.HTM

5. Canham CD (1988) An index for understory light levels in and around canopy gaps. Ecology 69: $1634-1638$

6. Elton CS (1958) The ecology of invasions by animals and plants. Methuen, London

7. Gómez-Aparicio L, Canham CD, Martin PH (2008) Neighbourhood models of the effect of the invasive Acer platanoides on the tree seedling dynamics: linking impact on communities and ecosystems. Journal of Ecology 96: 78-90

8. Gutiérrez J, Jones CG, Sousa R (2014) Toward an integrated ecosystem perspective of invasive species impact. Acta Oecologica 54:131-138

9. Herron PM, Martine CT, Latimer AM, Leicht-Young SA (2007) Invasive plants and their ecological strategies: prediction and explanation of woody plant invasion in New England. Divers Distrib, 13: 633-644

10. Higgins SI, Richardson DM, Cowling RM (1996) Modeling invasive plant spread: the role of plant-environment interactions and model structure. Ecology 77(7): 2043-2054

11. Huang S, Titus SJ, Wiens DP (1992) Comparison of nonlinear height-diameter functions for major Alberta tree species. Canadian Journal of Forest Research 22: 1297-1304

12. Hughes KA, Worland MR (2010) Spatial distribution, habitat preference and colonization status of two alien terrestrial invertebrate species in Antarctica. Antarctic Science 22(3): 221-231

13. Khaiter PA (1991) Modelling of anthropogenic dynamics of forest biogeocenoses. Znaniye, Kiev

14. Khaiter PA, Erechtchoukova MG (2007) Environmental assessment of anthropogenic impact through the patterns of ecosystem stress reactions. Int. J. Environ., Cultur. Econ. Social Sustainability 3(4): 179-189 
15. Khaiter PA, Erechtchoukova MG (2009) The notion of stability in mathematics, biology, ecology and environmental sustainability. In: Anderssen B et al. (eds.), Proceedings of the 18th IMACS World Congress - MODSIM09 International Congress on Modelling and Simulation, Cairns, Australia, pp 2265-2271

16. Khaiter PA, Erechtchoukova MG, Roushan S (2016) A Framework for Decision-Making in Cases of Invasive Species. In: Sauvage, S, Sánchez-Pérez JM, Rizzoli AE (eds.), Proceedings of the 8th International Congress on Environmental Modelling and Software, July 1014, Toulouse, France, pp 1210-1217

17. Lapointe M, Brisson J (2012) A comparison of invasive Acer platanoides and native A. saccharum first-year seedlings: growth, biomass distribution and the influence of ecological factors in a forest understory. Forests 3: 190-206. doi: 10.3390/f3020190

18. Mack RN (1996) Predicting the identity and fate of plant invaders: emergent and emerging approaches. Biol. Conserv 78: 107-121

19. Maguire LA (2004) What can decision analysis do for invasive species management? Risk Analysis 24(4): 859-868

20. Martin PH, Canham CD (2010) Dispersal and recruitment limitation in native versus exotic tree species: Life-history strategies and Janzen-Connell effects. Oikos 119: 807-824

21. Martin PH, Canham CD, Marks PL (2008) Why forests appear resistant to exotic plant invasion: intentional introductions, stand dynamics, and the role of shade tolerance. Front Ecol Environ 6: 142-149

22. Martin PH, Marks P (2006) Intact forests provide only weak resistance to a shade-tolerant invasive Norway maple (Acer platanoides L.). Journal of Ecology 94: 1070-1079

23. Mazza G, Tricarico E, Genovesi P, Gherardi F (2014) Biological invaders are threats to human health: an overview. Ethology Ecology \& Evolution 26(2-3): 112-129

24. Molnar JL, Gamboa RL, Revenga C, Spalding MD (2008) Assessing the global threat of invasive species to marine biodiversity. Frontiers in Ecology and the Environment 6(9): 485492

25. Morrison JA, Mauck K (2007) Experimental field comparison of native and non-native maple seedlings: Natural enemies, ecophysiology, growth and survival. J Ecol 95: 1036-1049

26. Murphy LE (2011) SORTIE-ND User Manual, Version 6.11. Institute of Ecosystem Studies, Millbrook, NY. http://www.sortie-nd.org/software/index.html

27. Nowak DJ Rowntree RA (1990) History and range of Norway maple. Journal of Arboriculture 16: 291-296

28. Ologundudu AF, Adelusi AA, Adekoya KP (2013) Effect of light stress on germination and growth parameters of Corchorus olitorius, Celosia argentea, Amaranthus cruentus, Abelmoschus esculentus and Delonix regia, Not Sci Biol 5(4): 468-475

29. Peper PJ, McPherson EG, Mori SM (2001) Equations for predicting diameter, height, crown width, and leaf area of San Joaquin Valley street trees. Journal of Arboriculture 27(6): 306317

30. Radosevich SR, Stubbs MM, Ghersa C.M (2003) Plant invasions: process and patterns. Weed Science 51(2): 254-259

31. Reinhart KO, Gurnee J, Tirado R, Callaway RM (2006) Invasion through quantitative effects: intense shade drives native decline and invasive success. Ecological Applications 16(5): 1821-1831

32. Rogers JP (2013) Invasion ecology of Acer platanoides in an old-growth urban forest. Environmental Science and Biology Theses, pp 1-74

33. Senbeta F, Teketay D (2001) Regeneration of indigenous tree species under the canopies of the tree plantations in central Ethiopia. J Trop Ecol 42: 175-185 
34. Shigesada N, Kawasaki K, Takeda Y (1995) Modelling stratified diffusion in biological invasion. American Naturalist 146: 229-251

35. Urgenson LS, Reichard SH, Halpern CB (2012) Multiple competitive mechanisms underlie the effects of strong invader on early- to late-seral tree seedlings. Journal of Ecology 100: 1204-1215

36. Vitousek PM, Walker LR, Whiteaker LD, Mueller-Dombois D, Matson PA (1987) Biological invasion by Myrica faya alters ecosystem development in Hawaii. Science 238: 802804

37. Walters MB, Reich PB (1996) Are shade tolerance, survival, and growth linked? Low light and nitrogen effects on hardwood seedlings. Ecology 77(3): 841-853

38. Wangen SR, Webster CR (2006) Potential for multiple lag phases during biotic invasions: reconstructing an invasion of the exotic tree Acer platanoides. Journal of Applied Ecology 43: $258-268$

39. Webb SL, Dwyer M, Kaunzinger CK, Wyckoff PH. (2000) The myth of the resilient forest: case study of the invasive Norway maple (Acer platanoides). Rhodora 102(911): 332-354

40. Webster CR, Jenkins M, Jose S (2006) Woody invaders and the challenges they pose to forest ecosystems in the eastern United States. J For 104: 366-374

41. Wyckoff PH, Webb SL (1996) Understory influence of the invasive Norway maple (Acer platanoides). Bulletin of the Torrey Botanical Club 123(3): 197-205

42. Yang RC, Kozak A, Smith JHG (1978) The potential of Weibull-type functions as a flexible growth curves. Canadian Journal of Forest Research 8: 424-431

43. Zhang L (1997) Cross-validation of non-linear growth functions for modelling tree heightdiameter relationships. Annals of Botany 79: 251-257 